\title{
Properties of gasoline with additives of combustion activators
}

\author{
Viktoriia Ribun $^{1}$, Sergiy Kurta $^{1}$, Mariia Penhryn $^{1}$ \\ 1-Department of chemistry Vasyl Stefanyk Precarpathian National University, UKRAINE, Ivano-Frankivsk, Halytska \\ st. 201/320, ribun.vika@gmail.com
}

\begin{abstract}
The paper deals with an analysis of the problems relating to the use of special additives for gasoline. The results of experimental tests of combustion activators confirm the possibility of improving of physical and chemical characteristics and combustion efficiency of gasoline with additives of paraacetaldehyde, cumene hydroperoxide and absolute ethyl alcohol.
\end{abstract}

Key words - gasoline, additives, oxygenates, ethanol, cumene hydroperoxide, paraatsetaldehyd, absolut ethanol, octane number.

The improvment of the internal combustion engine design put higher and higher requirements for gasoline, as motor fuel. These requirements can not be met by improving the fuel cleaning methods [1]. Nowadays, special additives, which improves fuel operational properties are added to the gasoline. They must be well dissolved in gasoline, do not cause clogging of filters and do not degrade other gasoline operational properties. All these requirements have led to the development of new special additives for gasoline to improve their properties. In the early 1950s, the problem of fuel seasonality was solved [2]. Today, the Ukrainian market offers a wide range of new brands of gasoline and additives produced by Ukrainian and foreign companies. [3]. However, modern technology of additive production has a number of disadvantages[4]. Therefore, the development of methods for improving gasoline properties using oxygen-generating additives is an important scientific and practical task.

The paper presents theoretical and practical studies of combustion activators and substances, which generate oxygen radicals in fuel. The solubility of ethyl alcohol, paraacetaldehyde and cumene hydroperoxide in gasoline has been studied. It is found that mixtures of gasoline and ethyl alcohol are unstable. Only absolute alcohol mixes with gasoline in any ratio and forms stable mixtures. Ethyl alcohol absolutization was carried out with various reagents. Although calcium oxide is an effective dehydrator, it is promising to use the tetrabutyl titanium. As a result of its hydrolysis, butyl alcohol is formed. Butanol can be used as a stabilizer of the gasoline-ethanol mixtures. [5].

The obtained results confirm the possibility of adjusting the density, combustion time and chemical stability of fuel using these additives. It was concluded that these additives, namely ethyl alcohol, are strategic for Ukraine, which has high potential for growing of raw materials for the bioethanol production.

\section{References}

[1] I. G Fuks, V. G. Spirkin, T. N. Shabalin. Fundamentals of Chemotology. Moscow: Publishing House "Oil and Gas" of the Russian State University of Oil and Gas named after I. M Gubkin, 2004.

[2] O. V. Zaychukova, O.V. Vasileva, V.O. Antonova. "Improvement of operational properties of fuel and lubricants with the help of additives". Science and Youth. Modern Aviation Technology, no. 10-12, p. 20-22, 2012

[3] S. L. Andreev, L. E. Kruglov, S. N Hadzhiev, VV Cheremin. "Estimation of octane number of catalytic cracking gasoline at change of quality of mixed raw materials", Chemistry and technology of fuels and oils, vol. 12, p. 25-26, 1991.

[4] A. A. Gureyev, V. S. Azev, Automobile gasoline. Properties and Application Moscow: Oil and Gas, 1996.

[5] V. S. Ribun, S. V. Fedorchenko, S.A.Kurta. "Properties of motor fuel with combustion activators" Bulletin of the Vasyl Stefanyk Precarpathian National University. Chemistry series, issue 19, p. 93-99, 2015. 